\title{
Sosialisasi Penyimpanan dan Pengamanan Dokumen Rekam Medis Di Rumah Sakit Surabaya Medical Services
}

\author{
Amir Ali $1^{*}$ \\ ${ }^{1}$ Stikes Yayasan Rumah Sakit Dr. Soetomo \\ e-mail: $\underline{\text { amir ali@stikes-yrsds.ac.id }}{ }^{1}$ \\ * Penulis Korespondensi: E-mail: amir_ali@stikes-yrsds.ac.id
}

\begin{abstract}
Surabaya Medical Service Hospital has a hospital management information system (SIMRS) called Medical Management Service (MMS). This MMS SIMRS will print the medical record number, but the printing of the medical record number still varies. There are number formats with 5 digit numbers, there are numbers followed by letters, with a sign (-), there are combinations of letters and numbers. Example: 353xx, C-0510xx, P000xx. The purpose of this community service activity is to socialize concepts and regulations related to storage, filing and security of medical record documents (DRM). The method in this activity is in the form of socialization activities carried out online. This activity was attended by 20 participants consisting of hospital employees from related units and students of the Dr.Soetomo Hospital Foundation stikes campus so that this event is more interactive because it does not only absorb knowledge from resource persons, but participants can ask questions and conduct discussions about storage systems. and DRM security. The achievement of the target material discussed by the resource persons is that everything has been conveyed, this is in accordance with what is written in the PPT format for socialization and delivery of material on storage systems, filing and DRM security. This can be seen from the participants' understanding of the material which can be seen from the results of the pretest and posttest given. The conclusion of this activity is that the participants' understanding of the material presented is achieved, where the average value of the posttest results has increased from the pretest results, from 78 to 99.17. In the future, mentoring activities will be carried out related to the implementation of DRM storage, alignment and security activities which are a continuation of this community service activity.
\end{abstract}

Keywords: SIMRS, MMS, filing, Medical Record Documents

\begin{abstract}
Abstrak
Rumah sakit Surabaya medical Service memiliki sistem informasi manajemen rumah sakit (SIMRS) yang bernama Medical Managemen Service (MMS). SIMRS MMS ini akan mencetak nomer rekam medis, namun pencetakan nomer rekam medis masih beragam. Ada yang berformat angka dengan 5 digit angka, ada yang angka diikuti huruf, dengan tanda (-), ada yang kombinasi huruf dan angka. Contoh : 353xx, C-0510xx, P000xx. Tujuan dari kegiatan pengabdian masyarakat ini yaitu untuk mensosialisasikan konsep dan regulasi terkait penyimpanan, penjajaran (filing) dan pengamanan dokumen rekam medis (DRM). Metode dalam kegiatan ini yaitu dalam bentuk kegiatan sosialisasi yang dilaksanakan secara daring. Kegiatan ini dihadiri oleh 20 peserta yang terdiri dari pegawai rumah sakit dari unit terkait serta mahasiswa kampus stikes Yayasan rumah sakit Dr.Soetomo sehingga acara ini bersifat lebih interaktif karena tidak hanya menyerap ilmu dari narasumber saja, tetapi peserta dapat bertanya dan melakukan diskusi tentang sistem penyimpanan dan pengamanan DRM. Ketercapaian target materi yang dibahas oleh narasumber adalah telah tersampaikan semua, hal ini sudah sesuai dengan apa yang tertulis dalam format PPT untuk sosialisasi dan penyampaian materi tentang sistem penyimpanan, penjajaran (filing) dan pengamanan DRM. Hal ini terlihat dari pemahaman peserta akan materi tersebut dimana terlihat dari hasil pretest dan posttest yang diberikan. Kesimpulan dari kegiatan ini yaitu pemahaman peserta terhadap materi yang disampaikan tercapai, dimana nilai rata-rata hasil dari posttestnya mengalami peningkatan dari hasil pretesnya yakni dari nilai 78 menjadi 99,17. Kedepan akan dilakukan kegiatan pendampingan terkait implementasi dari kegiatan penyimpanan, penjajaran dan pengamanan DRM yang merupakan kelanjutan dari kegiatan pengabdian masyarakat ini.
\end{abstract}


Kata kunci: SIMRS, MMS, filing, Dokumen Rekam Medis

\section{PENDAHULUAN}

Seperti yang kita ketahui penjajaran dokumen rekam medis adalah sistem penataan rekam medis dalam suatu sekuens yang khusus agar rujukan dan pengambilan kembali (retrieve) menjadi mudah dan cepat. Terdapat 3 (tiga) cara dalam sistem penjajaran rekam medis yaitu sistem alphabetical, alphanumerical, dan numerical. Sedangkan berdasarkan cara penjajarannya dibagi menjadi 3 (tiga) yaitu; Straight Numerical filing (SNF) atau sistem nomor langsung, Midle Digit Filing (MDF) atau sistem angka tengah, Terminal Digit Filing (TDF) atau sistem angka akhir

Rumah sakit Surabaya medical Service memiliki sistem manajemen informasi rumah sakit (SIMRS) yang bernama Medical Managemen Service (MMS).

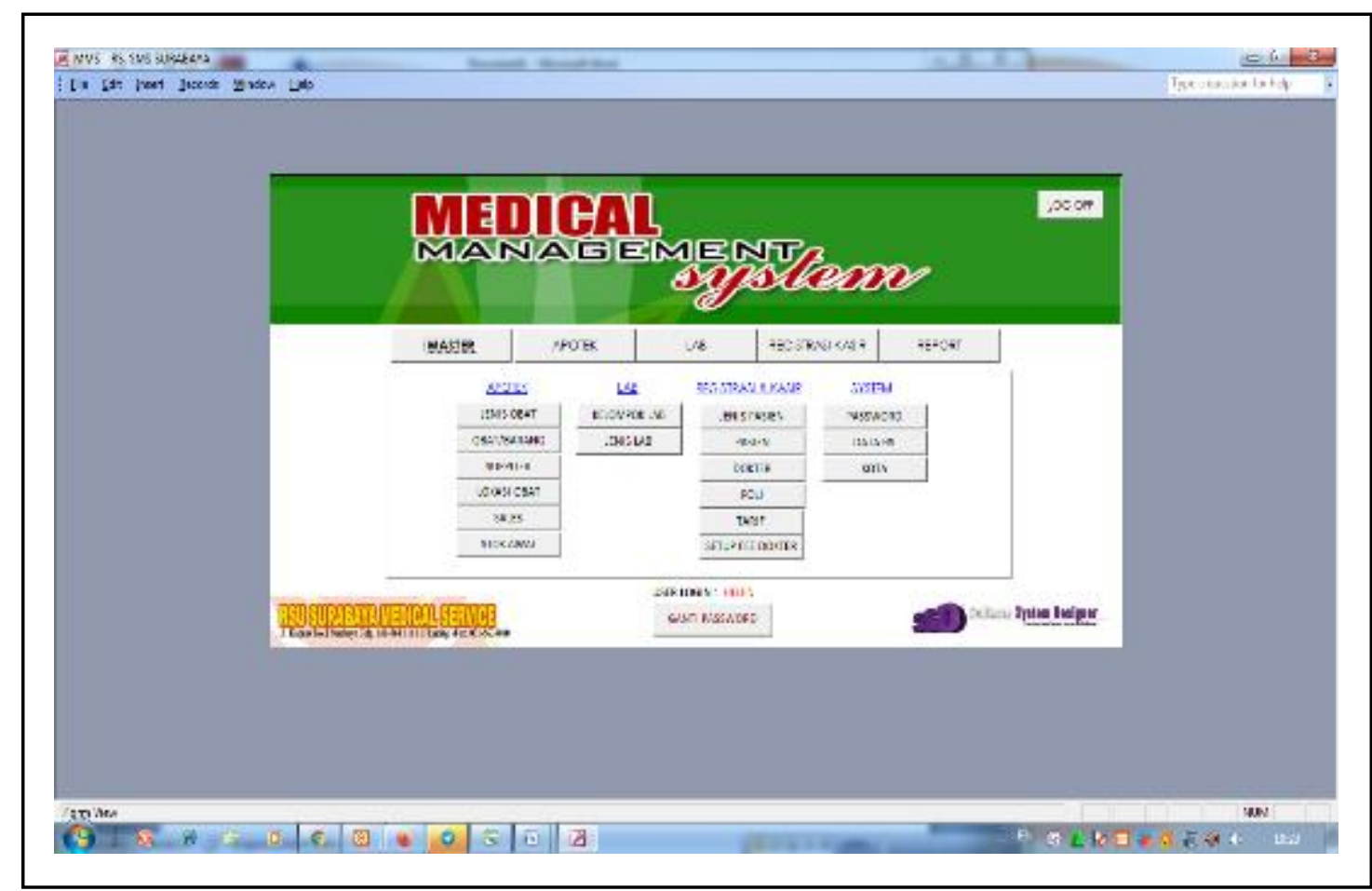

Gambar 1. User Interface Aplikasi SIMRS MMS dari RS SMS

Dalam SIMRS tersebut dapat mencetak nomer rekam medis bagi pasien yang berobat, tetapi pencetakan nomer rekam medis ini masih beragam. Ada yang berformat angka dengan 5 digit angka, ada yang angka diikuti huruf, dengan tanda (-), ada yang kombinasi huruf dan angka. Contoh : 353xx, C-0510xx, P000xx. Melihat akan kondisi yang demikian yang terjadi di Rumah Sakit Surabaya Medical Service, maka kami bermaksud melakukan kegiatan pengabdian masyarakat dalam bentuk sosialisasi penyimpanan dan pengamanan berkas rekam medis. Terkait dengan penyimpanan dokumen rekam medis ini tidak lepas dari pengaturan penomeran dokumen rekam medis, yang juga akan berpengaruh pada pengaturan penomerannya.

Dokumen rekam medis yang telah diatur penomerannya perlu dijaga secara system. Kaitannya dengan pengaturan penomeran dokumen rekam medis ini, maka diperluakan suatu system yang dapat mengamankan dokumen rekam medis ini secara softfile. Oleh 
karena itu akan dibuat suatu system SIMRS yang memfasilitasi akan pengaturan penomeran rekam medis yang baik sesuai dengan konsep dan teori yang benar sekaligus dilengkapi dengan system pengamanan akun dari pengguna system SIMRS tersebut.

System pengamanan akun ini diperlukan untuk mengamanan dokumen rekam medis dalam SIMRS yang dapat dilakukan dengan enkripsi. Enkripsi merupakan teknik dalam menyembunyikan password menjadi tulisan yang berubah dari bentuk aslinya. Enkripsi bertujuan untuk meningkatkan keamanan password dalam sebuah akun agar tidak disalahgunakan oleh orang yang tidak bertanggung jawab atau yang mempunyai kepentingan untuk melihat data sebuah aplikasi atau web

Dengan adanya system SIMRS yang teratur dalam penyimpanan pemberkasan dokumen rekam medis maka diharapkan tidak akan ditemukan dokumen rekam medis yang tidak sesuai dengan kaidah pemanfaatannya seperti tidak seragamnya penomeran dokumen rekam medis atau penggandaan dokumen rekam medis yang hal ini akan menyulitkan petugas rekam medis dalam menyajikannya terutama dalam melakukan pelayanan kepada pasien yang berobat. Tidak cuman dalam hal pelayanan kepada pasien, tetapi juga ketika melihat riwayat pasien terkait dengan tindakan medis yang dilakukan oleh dokter, tidak akan dijumpai ketika dokumen rekam medis ini hilang.

\section{METODE PELAKSANAAN}

Metode kegiatan ini dilaksanakan dalam bentuk kegiatan sosialisasi terkait penyimpanan, penjajaran (filing) dan pengamanan dokumen rekam medis. Kegiatan ini dihadiri oleh 20 peserta yang terdiri dari pegawai rumah sakit dari unit pendaftaran rawat jalan, rawat inap, pendaftaran pasien, IGD, pimpinan rumah sakit serta mahasiswa kampus Stikes Yayasan Rumah Sakit Dr. Soetomo. Kegiatan ini dilaksanakan secara daring dengan aplikasi zoom meeting.

\section{Langkah Kegiatan Pengabdian Masyarakat}

Metode yang dipilih untuk kegiatan sosialisasi ini dengan cara sebagai berikut:

1. Membagikan lembar pretest terkait mater yang akan diberikan

2. Membagikan bahan materi secara softfile dan memberikan pengetahuan terkait sosialisasi penyimpanan, penjajaran (filing) dan pengamanan dokumen rekam medis di rumah sakit surabaya medical service kepada peserta kegiatan pengabdian masyarakat

3. Memberikan lembar post test terkait materi yang telah diberikan

4. Tanya jawab dan diskusi interaktif

5. Pembuatan Laporan kegiatan pengabdian masyarakat di Rumah Sakit Surabaya medical service 
Membagikan bahan materi secara softfile dan memberikan pengetahuan terkait sosialisasi penyimpanan, penjajaran (filing) dan pengamanan dokumen rekam medis di rumah sakit surabaya medical service kepada peserta kegiatan pengabdian masyarakat

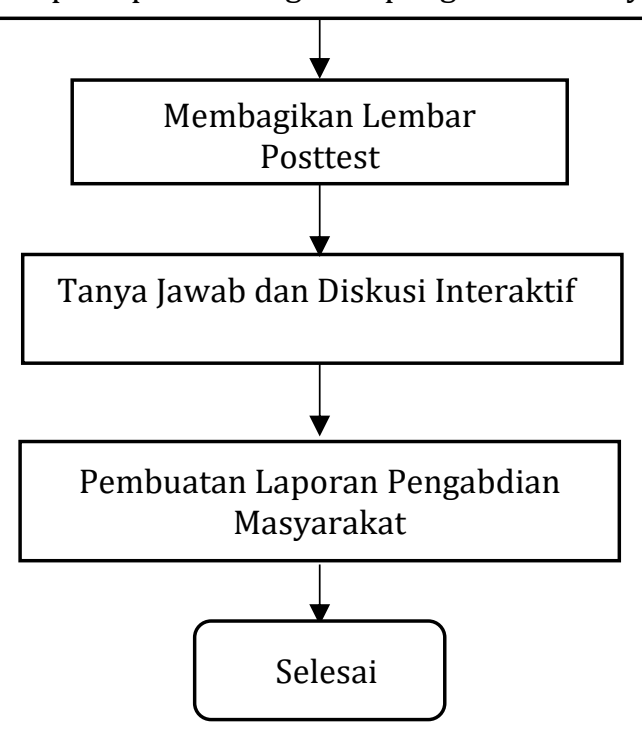

Gambar 2. Flowchart Kegiatan Pengabdian Masyarakat

\section{Tahapan Pelaksanaan Kegiatan}

Adapun penjelasan dari tahapan pelaksanaan kegiatan adalah sebagai berikut:

1. Persiapan, perijinan dan pemberitahuan meliputi:

a. Rapat intern panitia dan pembagian tugas.

b. Sosialisasi kepada tim/panitia

c. Surat ijin dan pemberitahuan rencana kegiatan kepada Rumah Sakit Surabaya medical service

2. Survey awal (penentuan sasaran peserta sosialisasi):
a. Pembuatan formulir pretest dan post test
b. Penyusunan dan penggandaan materi sosialisasi
c. Penetapan narasumber

3. Persiapan Sosialisasi
a. Penyusunan rencana jadwal pelaksanaan sosialisasi
b. Penentuan hari, tanggal, jam dan tempat pelaksanaan kegiatan.
c. Undangan kepada staf/pegawai rumah sakit peserta sosialisasi
d. Persiapan konsumsi, peralatan, perlengkapan dan komputer 
4. Pelaksanaan kegiatan

a. Pelaksanaan kegiatan sosialisasi dilaksanakan 2 hari selama masing-masing 2 jam

b. Jumlah staf/ pegawai rumah sakit sebanyak 5 orang

c. Selama seminar berlangsung, seluruh staf/ pegawai rumah sakit harus tunduk dan patuh pada tata tertib yang dibuat oleh panitia.

d. Semua staf/ pegawai rumah sakit akan mendapatkan materi sosialisasi

e. Seluruh staf/ pegawai rumah sakit mendapatkan snack dan minuman.

5. Evaluasi kegiatan

a. Usai kegiatan dilaksanakan, panitia mengadakan evaluasi kegiatan.

b. Hasil evaluasi kegiatan akan ditindaklanjuti dalam bentuk laporan tertulis.

c. Laporan hasil evaluasi kegiatan akan dijadikan umpan balik serta perbaikan untuk rencana kegiatan berikutnya kepada pihak-pihak berkaitan apabila diperlukan

6. Pembuatan laporan

a. Usai kegiatan dilaksanakan, maka laporan pengmas dibuat

b. Dilengkapi dengan dokumen misalnya dokumen kehadiran secara online, pretest dan post test, lampiran materi

\section{HASIL dan PEMBAHASAN}

\section{HASIL}

Kegiatan pengabdian masyarakat berupa pemberian sosialisasi ini telah dapat berjalan dengan baik dan lancar. Kegiatan ini dilaksanakan melalui metode pemberian materi tentang sistem penyimpanan dan penjajaran (filing) dokumen rekam medis beserta pengamanan rekam medis dan kemudian dilanjutkan dengan diskusi tanya jawab dengan pegawai rumah sakit khususnya bagian rekam medis.

Kegiatan ini dihadiri oleh 20 peserta yang terdiri dari pegawai rumah sakit dari unit pendaftaran rawat jalan, rawat inap, pendaftaran pasien IGD, pimpinan rumah sakit serta mahasiswa kampus stikes Yayasan rumah sakit Dr.Soetomo sehingga acara ini bersifat lebih interaktif karena tidak hanya menyerap ilmu dari narasumber saja, tetapi pegawai rumah sakit dapat bertanya dan melakukan diskusi tentang sistem penyimpanan, penjajaran (filing) dan pengamanan dokumen rekam.

Kegiatan ini dilaksanakan hari selasa dan rabu, 04 dan 05-Mei-2021 dari pukul 09.00 sampai dengan pukul 12.00 WIB. Mulai dilakukan persiapan oleh ketua panitia, anggota panitia, mahasiswa dan pegawai rumah sakit Surabaya Medical Service. Peserta kegiatan berjumlah 20 yang terdiri dari pegawai rumah sakit Surabaya Medical Service dan mahasiswa Stikes Yayasan Rumah Sakit Dr.Soetomo. Susunan acara Sosialisasi ini adalah :

1. Persiapan dengan melakukan absensi online untuk peserta kegiatan pengabdian masyarakat

2. Mengisi kuesioner pre test sebelum acara pemaparan secara online

3. Pemberian edukasi sosialisasi tentang sistem penyimpanan dan penjajaran (filing) dokumen rekam medis dan Pengamanan dokumen rekam medis oleh : Amir Ali, S.Kom., M.Kom

4. Diskusi dan tanya jawab yang dipandu langsung oleh narasumber dari STIKES Yayasan RS.Dr.Soetomo Surabaya

5. Dokumentasi dan foto pelaksanaan kegiatan secara online

6. Mengisi kuesioner post test setelah acara pemaparan secara online 


\section{PEMBAHASAN}

Hasil kegiatan pengabdian masyarakat secara garis besar mencakup beberapa komponen sebagai berikut:

1. Keberhasilan target jumlah pegawai yang hadir dalam sosialisasi

Target pegawai yang hadir dalam sosialisasi adalah seperti direncanakan sebelumnya adalah 20 orang. Dalam pelaksanaannya, kegiatan ini diikuti oleh 20 orang peserta. Dengan demikian dapat dikatakan bahwa target peserta tercapai $100 \%$, hal ini disertai dengan absensi kehadiran tiap undangan.

2. Ketercapaian target materi yang dibahas oleh narasumber

Ketercapaian target materi yang dibahas oleh narasumber adalah telah tersampaikan semua, hal ini sudah sesuai dengan apa yang tertulis dalam format PPT untuk sosialisasi dan penyampaian materi tentang sistem penyimpanan dan penjajaran (filing) dokumen rekam medis beserta pengamanan rekam medis. Materi yang disampaikan dapat dipahami oleh peserta, dimana hal ini terlihat dari peningkatan nilai rata-rata hasil test yang diberikan, dimana nilai rata-rata posttestnya mengalami peningkatan dari nilai rata-rata pretestnya dari nilai 78 menjadi 99,17. Sehingga hal ini dikatakan mengalami peningkatan pemahaman akan materi yang disampaikan.

3. Ketersediaan penggunaan lokasi sosialisasi secara online

Lokasi sosialisasi secara online di laksanakan melalui jaringan internet masingmasing peserta.

4. Ketersediaan sarana dan prasarana seperti: meja, kursi, komputer, kamera, sound sistem, aplikasi video teleconference : Zoom

Untuk sarana dan prasarana dalam kegiatan pengabdian masyarakat ini telah tersedia dengan baik. Masing2 peserta menggunakan meja, kursi dan laptop masingmasing yang dilengkapi dengan camera serta aplikasi video teleconference zoom.

5. Dokumentasi kegiatan sosialisasi

Untuk pendokumentasian dari kegiatan ini dilakukan oleh panitia pendukung dari kegiatan pengabdian masyarakat. Dengan mengcapture tiap kegiatan dari sosialisasi yang disampaikan oleh pemateri.

\section{PENYIMPANAN DRM}

Sistem penyimpanan berdasarkan lokasi penyimpanannya terdiri dari 2 (dua) cara yaitu sentralisasi dan desentralisasi (Ritonga, Zulham Andi. Sari, 2019). 2 (dua) tersebut yaitu:

1. Sistem Sentralisasi

Sentralisasi ini diartikan penyimpanan dokumen rekam medis seorang pasien dalam satu kesatuan baik catatan kunjungan gawat darurat, rawat jalan maupun catatan selama pasien di rawat inap.

2. Sistem Desentralisasi

Desentralisasi terjadi pemisahan antara dokumen rekam medis gawat darurat, poliklinik (rawat jalan) dengan rekam medis rawat inap. 


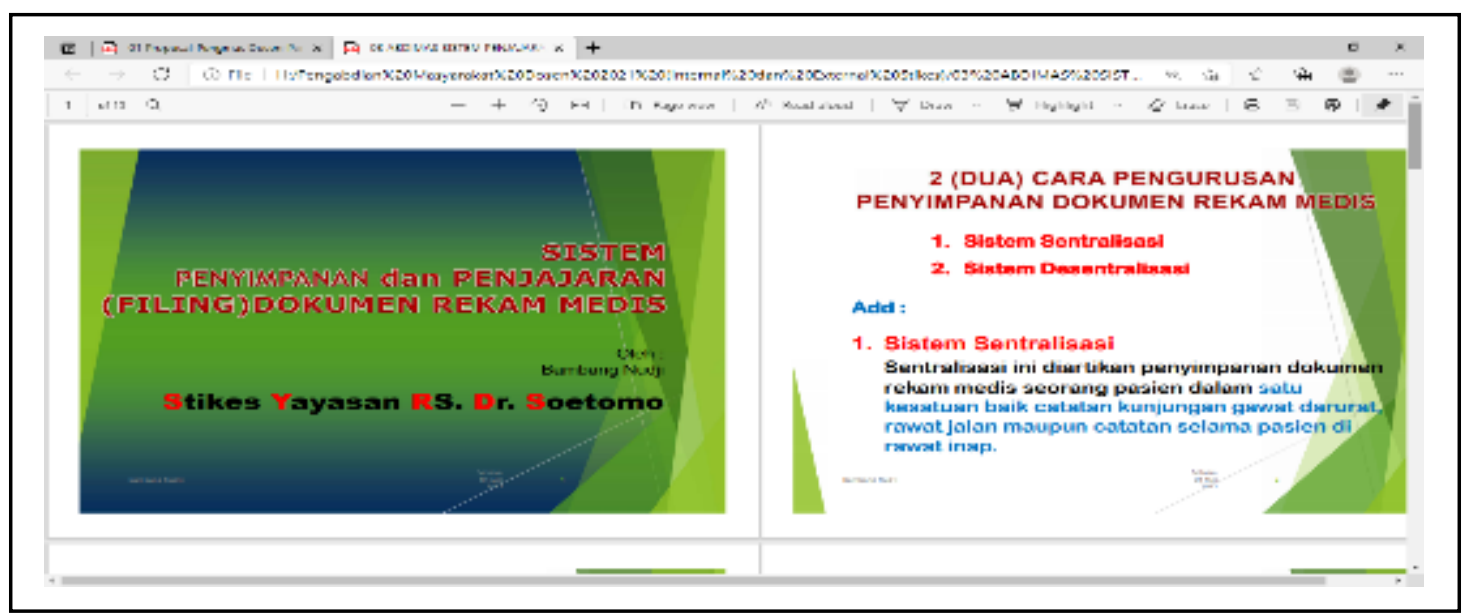

Gambar 3. Materi Sosialisasi Terkait Penyimpanan Dokumen Rekam Medi

\section{PENJAJARAN DRM}

Penjajaran adalah sistem penataan rekam medis dalam suatu sekuens yang khusus agar rujukan dan pengambilan kembali (retrieve) menjadi mudah dan cepat (Ritonga, Zulham Andi. Sari, 2019). Terdapat 3 (tiga) cara dalam sistem penjajaran rekam medis yaitu sistem alphabetical, alphanumerical, dan numerical. Menurut Budi,2011 dalam Karya Tulis Ilmiah (KTI) (NurIslamiyah, 2020) berdasarkan cara penjajarannya dibagi menjadi 3 (tiga) yaitu; Straight Numerical filing (SNF) atau sistem nomor langsung, Midle Digit Filing (MDF) atau sistem angka tengah, Terminal Digit Filing (TDF) atau sistem angka akhir.

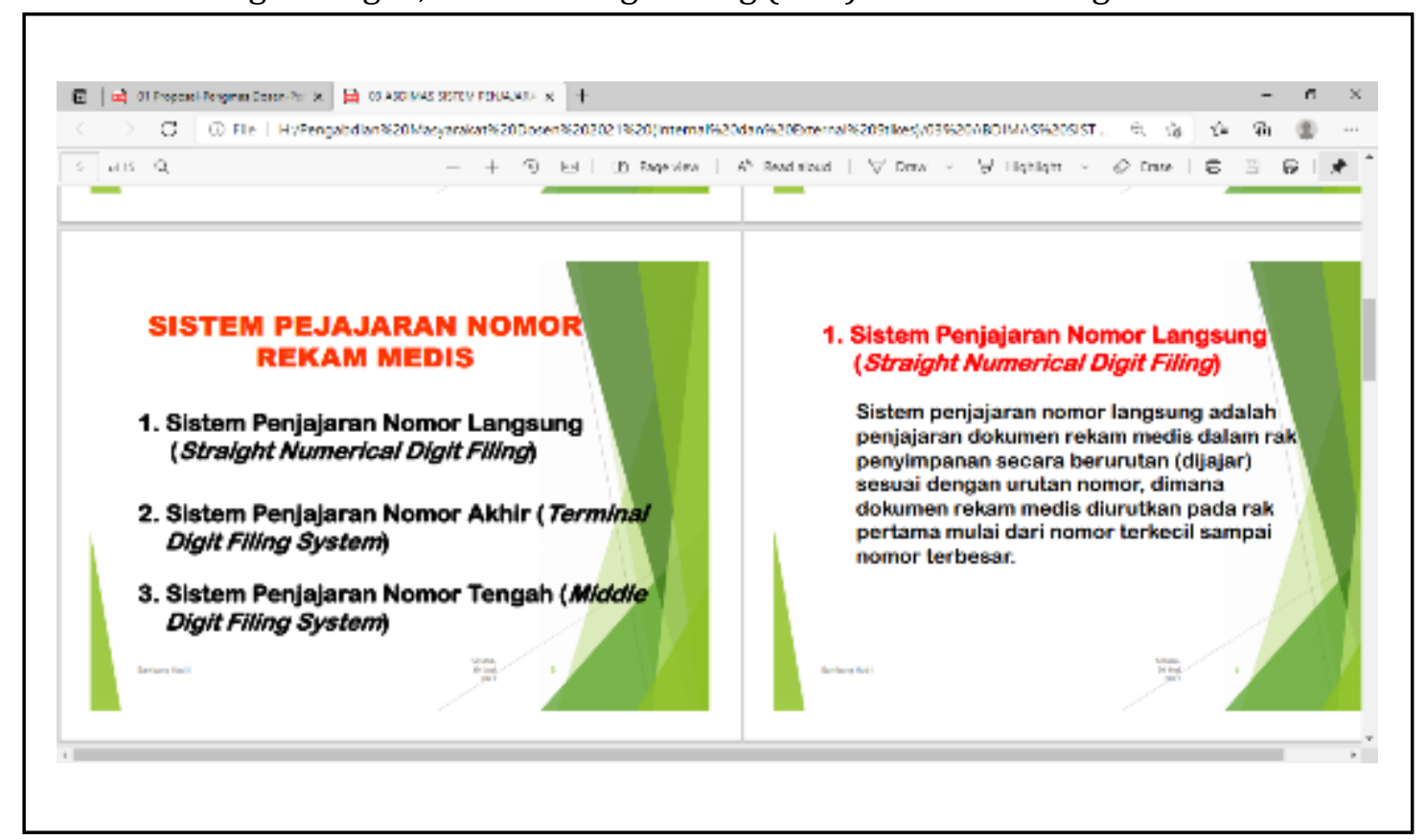

Gambar 4. Materi Sosialisasi Terkait Penjajaran Dokumen Rekam Medis

Sistem penjajaran nomor langsung (Straight Numerical Digit Filing) adalah penjajaran dokumen rekam medis dalam rak penyimpanan secara berurutan (dijajar) sesuai dengan urutan nomor, dimana dokumen rekam medis diurutkan pada rak pertama mulai dari nomor terkecil sampai nomor terbesar. Sedangkan Sistem penjajaran angka tengah (Middle Digit Filing System) adalah penjajaran dokumen rekam medis dalam rak 
penyimpanan yang dikelompokan menjadi 3 kelompok angka, masing-masing 2 angka. Angka pertama adalah kelompok dua angka yang terletak tengah, angka kedua adalah kelompok dua angka yang terletak dikiri dan angka ketiga adalah kelompok dua angka terletak paling kanan. Untuk Sistem penjajaran nomor akhir (Terminal Digit Filing System) adalah penjajaran dokumen rekam medis dalam rak penyimpanan yang dikelompokan menjadi 3 kelompok angka, masing-masing 2 angka. Angka pertama adalah kelompok dua angka yang terletak dipaling kanan, angka kedua adalah kelompok dua angka yang terletak ditengah dan angka ketiga adalah kelompok dua angka terletak paling kiri.

Hal-hal yang perlu diperhatikan dalam sistem penyimpanan dokumen rekam medis dengan menggunakan sistem penjajaran apapun, antara lain :

1. Sortir atau urutkan sesuai dengan sisten penjajaran yang ada,

2. Penjajaran atau peletakan dokumen rekam medis, nomor dokumen rekam medis yang paling kecil yang paling jauh, makin dekan dengan badan kita makin besar.

3. Menurut Waktu penyimpanan sesuai Peraturan Menteri Kesehatan Republik Indonesia Nomor : 269/Menkes/Per/III/2008, pasal 8 adalah lamanya penyimpanan rekam medis sekurang-kurangnya untuk jangka waktu 5 (lima) tahun, terhitung dari tanggal terakhir pasien berobat atau dipulangkan, masa aktif dokumen rekam medis.

4. Pengelolaan dan penataan dokumen rekam medis pada rak penyimpanan diperlukan kode warna. Kode warna yang dibakukan pada setiap sampul rekam medis pada 2 (dua) angka akhir diberi warna. Masing-masing terdiri dari 10 (sepuluh) angka, dimulai dari 0 s/d. 9 menjadi kode warna yang dalam penerapannya.

5. Sebaikan sistem penjajaran dokumen rekam medis menggunakan Sistem Penjajaran Nomor Akhir (Terminal Digit Filing System)

6. Modifikasi dari 100 rak menjadi 10 rak.

\section{PENGAMANAN DRM}

Untuk login dan menggunakan SIMRS, tentunya dibutuhkan username dan password. Username dan password ini diimplementasikan dalam bentuk akun dalam SIMRS. Akun ini perlu dilakukan enkripsi terhadap passwordnya. Agar pengguna aman, tidak dapat di lihat passwordnya oleh pihak yang tidak berwenang. Enkripsi merupakan teknik dalam menyembunyikan password menjadi tulisan yang berubah dari bentuk aslinya. Enkripsi bertujuan untuk meningkatkan keamanan password dalam sebuah akun agar tidak disalahgunakan oleh orang yang tidak bertanggung jawab atau yang mempunyai kepentingan untuk melihat data sebuah aplikasi atau web (Kadri, 2020). 


\section{AKUN DALAM SIMRS}

- Setiap pengguna dalam modul di SIMRS menggunakan akun masing-masing

- Akun ini perlu dilakukan kegiatan enkripsi akun agar tidak mudah dikenali

- Akun dalam modul di SIMRS di implementasikan dalam bentuk password

- Enkripsi password dalam akun pengguna SIMRS di enkripsi dengan suatu algoritma, salah satunya algoritma MD5

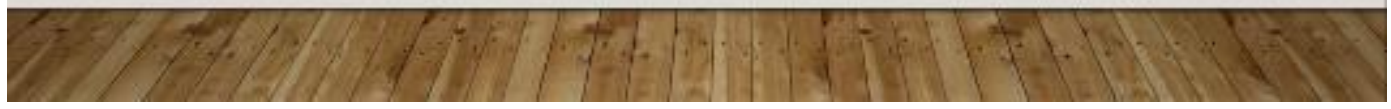

Gambar 5. Materi Sosialisasi Akun dalam SIMRAS

\section{ENKRIPSI PASSWORD}

- Terkait dengan enkripsi ini, kica mengenal ilmu kriptografi

- Kriptografi merupakan ilmu yang mempelajari tentang pengamaran data atau informasi

- IImu ini dapat kita terapkan pada pengamanan berkas rekam medis secara elektronik

Gambar 6. Materi Sosialisasi Terkait Enkripsi Password dalam SIMRS

Peserta dalam hal ini pegawai rumah sakit yang hadir dan mahasiswa stikes Yayasan RS Dr.Soetomo adalah sangat antusias terutama pada sesi tanya jawab, maka dapat disimpulkan bahwa tujuan penyampaian materi dan pemaparan konsep tentang penyimpanan dan penjajaran serta pengamanan dokumen rekam medis bagi rumah sakit ini dapat tercapai dan adanya kesesuaian materi sosialisasi dengan judul pelaksanaan. 
Untuk penggunaan lokasi sosialisasi menggunakan video teleconference dengan memanfaatkan aplikasi zoom.

Berikut dokumentasi pelaksanaan kegiatan sosialisasi penyimpanan dan penjajaran serta pengamanan dokumen rekam medis bagi rumah sakit :

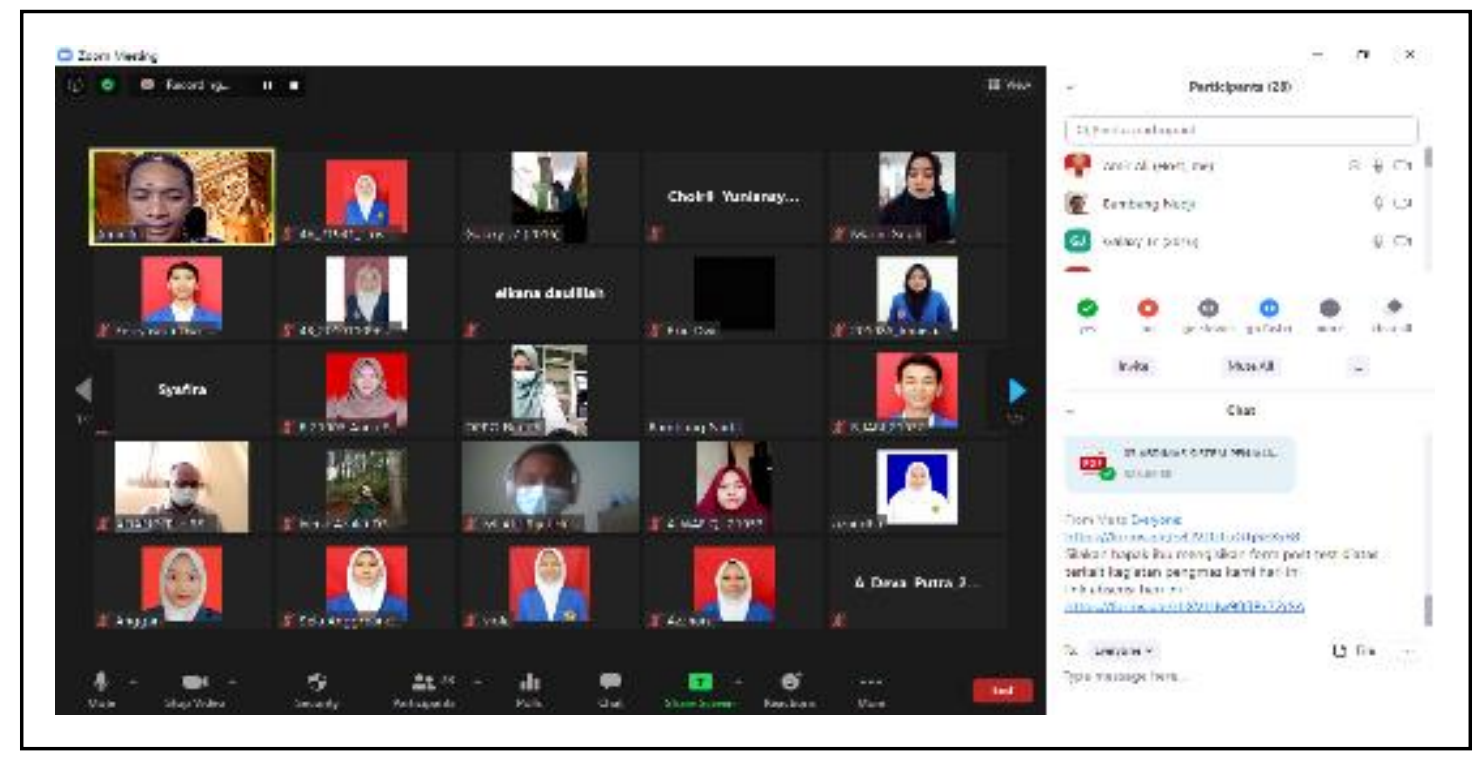

Gambar 7. Screen Shoot Kegiatan Pengabdian Masyarakat Secara Daring Dalam Bentuk Sosialisasi Terkait Penyimpanan, Penjajaran dan Pengamanan Dokumen Rekam Medis

\section{KESIMPULAN}

Program pengabdian masyarakat melalui sosialisasi ini dapat diselenggarakan dengan baik dan berjalan dengan lancar sesuai dengan rencana kegiatan yang telah disusun. Pengetahuan dan pemahaman serta ketertarikan peserta tentang materi sosialisasi yang disampaikan bertambah. Hal ini terbukti dengan adanya kegiatan tanya jawab seputar Penyimpanan, Penjajaran dan Pengamanan Dokumen Rekam Medis bagi rumah sakit baik dari segi penggunaannya dan manfaatnya. Kegiatan ini mendapat sambutan sangat baik terbukti dengan keaktifan peserta melalui banyaknya pertanyaan yang diajukan melalui forum tanya jawab. Diharapkan ke depan dapat menjalin kerjasama kembali melalui pemberian edukasi dengan tema yang berbeda.

Program pengabdian masyarakat memberikan pengetahuan bahwasannya :

1. Sistem penyimpanan berdasarkan lokasi penyimpanannya terdiri dari 2 (dua) cara:

a. Sentralisasi

b. Desentralisasi

2. Penjajaran dokumen rekam medis berdasarkan cara penjajarannya dibagai menjadi 3 yaitu

a. Straight Numerical filing (SNF)

b. Midle Digit Filing (MDF)

c. Terminal Digit Filing (TDF)

3. Pengamanan dokumen rekam medis

Pengamanan dokumen rekam medis dalam SIMRS dapat dilakukan dengan enkripsi. 


\section{UCAPAN TERIMAKASIH}

Terima kasih kepada rumah sakit Surabaya Medical Services yang telah memfasilitasi pada kegiatan pengabdian masyarakat ini. Terima kasih juga kami sampaikan kepada akademika khususnya mahasiswa Stikes Yayasan Rumah Sakit Dr. Soetomo yang juga ikut berperan aktif baik sebagai panitia sekaligus peserta dalam kegiatan pengabdian masyarakat. Semoga kegiatan ini membawa manfaat

\section{DAFTAR PUSTAKA}

Kadri, Y. (2020). Penerapan algoritma md5 sebagai pengaman akun pada aplikasi web emusrenbang kota binjai. Jurnal Teknik Informatika Kaputama (JTIK), 4.

NurIslamiyah, F. (2020). Literature review analisis sistem penyimpanan dokumen rekam medis rumah sakit.

Ritonga, Zulham Andi. Sari, F. M. (2019). Tinjauan sistem penyimpanan berkas rekam medis di rumah sakit umum pusat h adam malik tahun 2019. jurnal ilmiah perekam dan informasi kesehatan imelda, 4. 